\title{
Cómo convertir el aspecto en tiempo: traducción del zapoteco al español
}

\author{
Francisco Arellanes Arellanes \\ Universidad Nacional Autónoma de México \\ francisco_arellanes@yahoo.com.mx
}

Recibido: 28 de noviembre de 2012

Aceptado: 30 de marzo de 2013

\section{RESUMEN}

En este trabajo se plantea la problemática de traducir una narración de una lengua que codifica en el nivel flexivo fundamentalmente valores aspectuales (zapoteco) a una lengua que lo que codifica flexivamente es fundamentalmente valores temporales (español). Como resultado de lo anterior, un traductor no profesional puede producir ciertas construcciones anómalas desde el punto de vista de la lengua meta (v. gr. una serie de oraciones traducidas con flexión de pretérito imperfecto seguida de una serie de oraciones flexionadas en presente, sin que haya una aparente motivación para el cambio flexivo). Se argumenta que tales fenómenos no deben verse simplemente como errores atribuibles a una escasa competencia del traductor en la lengua meta, sino que pueden verse como el resultado de la tensión generada entre lo que cada lengua codifica y lo que de cada lengua se infiere.

Palabras clave: traducción, zapoteco, español, aspecto, flexión verbal.

How to Convert Aspect into Time: Translation from Zapotec into Spanish

\begin{abstract}
This article explores the difficulties of translating a narrative from a language that predominantly encodes aspectual information in its verbal inflection (Zapotec) to a language that by and large encodes temporal information in its verbal inflection (Spanish). As a consequence of this, an untrained translator may produce structures that are considered anomalous in the target language (e.g. a body of sentences in the imperfect preterite tense followed by a body of sentences in the present tense, without there being any apparent reason for the change in tense). It is argued that such phenomena should not simply be put down as errors owing to the translator's lack of competence in the target language, but that they can be seen as the result of the conflict that arises out of what each language encodes and what each language presumes.
\end{abstract}


Keywords: translation, Zapotec, Spanish, aspect, verbal inflection.

Sumario: 1. Propósito. 2. La variante de zapoteco y el sistema de escritura usado en el cuento analizado. 3. Los tipos de traducción. 4. Distinciones aspectuales en la morfología flexiva verbal en español. 5. Categorías flexivas en el zapoteco de San Pablo Güilá. 6. De vuelta a la flexión verbal en español. 7. Dos estilos narrativos y dos usos del aspecto flexivo en español. 8. Análisis de la flexión verbal en la traducción del cuento.

\section{Propósito}

Las nociones de tiempo y aspecto no son fáciles de diferenciar en el ámbito gramatical. El aspecto especifica el tiempo interno de un evento o se enfoca en una fase sobresaliente de desarrollo o modificación del evento (Cf. Comrie (1976), Smith, (1997), entre muchos otros). El tiempo, por su parte, ubica el momento en que un evento ocurre respecto del momento del habla o respecto de otro evento que se toma como punto de referencia. De tal modo, el tiempo tiene un carácter deíctico del cual carece el aspecto. En las lenguas humanas, el aspecto se puede codificar en el propio lexema verbal (aktionsart) o mediante recursos flexivos, derivativos, perifrásticos o léxicos (predominantemente adverbiales). El tiempo, por su parte, típicamente se codifica mediante recursos flexivos y mediante recursos léxico-adverbiales. Centrándonos exclusivamente en los recursos flexivos, se pueden distinguir lenguas que marcan tiempo de lenguas que marcan aspecto, es decir, lenguas con flexión temporal y lenguas con flexión aspectual. Se ha propuesto, por ejemplo, que el alemán es una lengua que carece de flexión aspectual y sólo tiene flexión temporal; las lenguas eslavas estarían en la situación opuesta (Comrie 1976). Desde esta perspectiva, el español se considera una lengua tempo-aspectual en la que, sin embargo, los valores temporales predominan mientras que los valores aspectuales son marginales (Mel'cuk 1993). Las lenguas zapotecas, por el contrario, se consideran lenguas típicamente aspectuales en las que los valores temporales son escasos o, incluso, inexistentes en el nivel flexivo (cf. Suárez (1983), Marlett y Pickett (1987), López Cruz (1997) Black (2000), entre otros). Dado que en español la flexión proporciona sobre todo información temporal, la información aspectual se tiene que codificar mediante otros medios o se tiene que inferir. En las lenguas zapotecas, en cambio, la flexión verbal explicita la información aspectual y son los valores temporales los que se tienen que inferir o expresar mediante otros medios.

Ante esta situación, la traducción del zapoteco al español implica, entre otras dificultades, convertir expresiones en las que el tiempo se infiere a partir del aspecto en expresiones en las que el tiempo tiene que estar codificado flexivamente y el aspecto debe inferirse o expresarse mediante otros recursos léxico o perifrásticos. De lo anterior se deriva que cuando los hablantes de zapoteco traducen expresiones lingüísticas de su lengua materna al español, en ocasiones hacen uso de la flexión temporal del español sustituyendo formas flexivas - correspondientes a tiempos distintos, pero con propiedades aspectuales muy similares- que un hablante nativo de español jamás haría. Por ejemplo, puede darse un cambio de un pretérito imperfec- 
to a un presente, como en el siguiente caso (las formas verbales están remarcadas en negritas) ${ }^{1}$ : "Allí amarraba las patas de sus burros. A las doce en punto, los llevaba al río para que bebieran agua. Cuando terminan de beber agua entonces los va a dejar de nuevo al potrero." De manera superficial, este tipo de "errores" podría atribuirse a una competencia gramatical insuficiente sobre el español por parte del traductor (hablante nativo de zapoteco). El propósito de este trabajo es mostrar que dichos usos aparentemente inapropiados de la flexión temporal del español revelan un conflicto entre la gramática de las dos lenguas y no pueden reducirse a una cuestión de incompetencia gramatical.

\section{La variante de zapoteco y el sistema de escritura usado en el cuento analizado}

El texto en zapoteco cuya traducción se analiza corresponde a la variante hablada en la comunidad de San Pablo Güilá, Oaxaca, México. El zapoteco de San Pablo Güilá es una variante zapoteca de los valles centrales, ágrafa hasta hace muy poco. El autor del texto, Federico Luis Gómez (Dǐ̌ kw Xàybè) es hablante nativo de esta variante de zapoteco. Actualmente tiene 29 años de edad y vive en la ciudad de México con su esposa Alicia (también hablante nativa de zapoteco) y sus dos hijos. Es programador analista por el Instituto Politécnico Nacional (IPN) y tiene un dominio bastante elevado del español y un dominio incipiente del inglés como segundas lenguas. Nuestra colaboración lingüística se remonta al verano de 2001. Luis Gómez se alfabetizó en su lengua materna siendo ya adulto. Para el cuento, usó un sistema de escritura desarrollado por Arellanes (2007) que consideraba criterios tipográficos y fonético-fonológicos en la elección de grafías (Cf. Arellanes 2009). El texto original está escrito en zapoteco y es del año 2009. Fue adaptado en su forma ortográfica al sistema de escritura desarrollado por el equipo de trabajo Làa'z xtizanu / Laa'dxy xtizizya / Laa'dx xtii'dxzahn (El corazón de nuestro zapoteco), fundado por los lingüistas y hablantes nativos de zapoteco de valles centrales Roberto Padilla (Escuela Normal Bilingüe e Intercultural de Oaxaca, ENBIO), Aurea López Cruz (Instituto Nacional de Antropología e Historia, INAH) y Alejandro Luis Gómez (ENBIO) $y$ al que nos hemos sumado otros lingüistas no hablantes nativos de zapoteco como Mario Chávez Peón (Centro de Investigaciones y Estudios Superiores en Antropología Social, CIESAS), Rosa María Rojas Torres (Instituto Nacional de Lenguas Indígenas, INALI) y Francisco Arellanes (Universidad Nacional Autónoma de México, UNAM). A continuación se muestra la correspondencia entre fonemas y grafías. Para los fonemas se siguen las convenciones del Alfabeto Fonético Internacional (AFI) mientras que para las grafías, como ya se dijo, se siguen las convenciones desarrolladas por el grupo denominado El corazón de nuestro zapoteco:

\footnotetext{
${ }^{1}$ Este es un pequeño fragmento de la traducción del texto zapoteco que se analiza más adelante.
} 
Consonantes fuertes:

AFI

Ortografía $p$

$\begin{array}{lcccccccc}\mathrm{k} & \mathrm{ts} & \mathrm{t} & \mathrm{s} & \mathrm{f} & \mathrm{m} & \mathrm{n} & 1 & \mathrm{r} \\ \mathrm{k} & \mathrm{ts} & \mathrm{tx} & \mathrm{s} & \mathrm{x} & \mathrm{m} & \mathrm{n} & 1 & \mathrm{r}\end{array}$

Consonantes débiles:

AFI $b$

Ortografía b

d

Timbres vocálicos:

$\begin{array}{ll}\text { AFI } & \text { i } \\ \text { Ortografía } & \text { i }\end{array}$

$\mathrm{e}$

e

$\mathrm{g}$
$\mathrm{g} / \mathrm{g}$

$\mathrm{z} \quad 3$

$-$

n̆ $\breve{\mathrm{I}} \quad \check{\mathrm{r}}$

Tipos de voz:

$\begin{array}{llll}\text { AFI } & \text { a } & \text { a } & \text { a ? } \\ \text { Ortografía } & \text { a } & \text { à } & \text { a' }\end{array}$

Tonos

AFI

Ortografía

7

á $\dot{t}$
$\dot{\mathbf{t}}$

a

$\mathrm{a} / \alpha$ n $\quad \underline{1}$

$\underline{\mathrm{r}}$

o

O

\section{Los tipos de traducción}

La tipología de la traducción es muy amplia. Aquí sólo voy a referirme a los criterios que me permitan caracterizar adecuadamente el texto traducido que se analiza en el presente trabajo. Según la lengua materna del traductor, la traducción puede ser: i) de L2 a L1 (por ejemplo, un hablante nativo de español traduce del inglés al español); ii) de L1 a L2 (por ejemplo un hablante nativo de rumano traduce del rumano al ruso). Bajo una perspectiva demasiado normativa de la traducción, nunca se puede (o debe) traducir de L1 a L2. Sin embargo, en las lenguas que carecen de una tradición literaria y del prestigio asociado a ésta -como es el caso del zapoteco- suele haber también carencia de aprendices con un alto grado de competencia de la lengua como L2, de modo que la traducción de L1 a L2 muy a menudo resulta la única estrategia posible para que la lengua se traduzca. El interés de traducir desde una L1 minoritaria hacia una L2 con más prestigio se ha acentuado en México a raíz de la aparición de concursos literarios en lenguas indígenas que piden como requisito no sólo el texto literario en la lengua materna sino también una traducción al español. Tal es el caso del Premio Nezahualcóyotl de Literatura en Lenguas Mexicanas de cuya convocatoria en el año 2012 se muestra un extracto a continuación: 


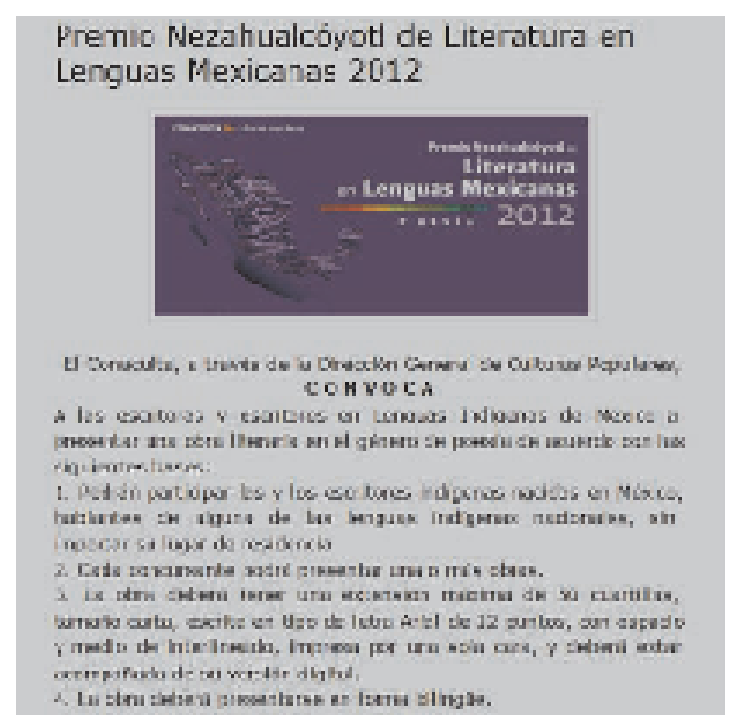

Según el tipo de texto traducido, las posibilidades son bastante amplias: i) traducción de textos científicos; ii) de textos literarios; iii) de textos legales (títulos académicos, testamentos, actas de nacimiento), etc. Incluso para cada uno de estos tipos de texto se pueden hacer subdivisiones bastante pertinentes: no es lo mismo traducir un texto sobre física cuántica que sobre lingüística antropológica; ni, por supuesto, se siguen los mismos criterios al traducir teatro que narración o que poesía, etc.

Un tercer criterio para distinguir tipos de traducciones consiste en diferenciar los casos en que exista o no una tradición de traducción recíproca entre las lenguas involucradas. Así, tenemos casos de traducción entre lenguas con una tradición que ha creado patrones, fórmulas y reglas tanto en el nivel morfosintáctico como en el nivel léxico ( $v . g r$. entre español y francés), mientras que en otros casos no existe dicha tradición (v. gr. entre el malayo y el vasco) y, por lo tanto, no existen demasiadas ideas apriorísticas, ni criterios sobre cómo traducir de una de las lenguas a la otra.

Finalmente, también resulta relevante determinar dónde está el foco de interés de la traducción. Hay casos en los que el reto está en traducir estructuras morfosintácticas entre lenguas muy diferentes gramaticalmente. Mientras que en otros casos, el reto está en traducir "el pensamiento", las ideas, la ideología, el sentir de un autor en específico. Evidentemente, el primer tipo de traducción tiene un interés mucho mayor para la lingüística que el segundo.

El foco de atención de este trabajo está, entonces, en un tipo de traducción con las siguientes características: de L1 a L2 (aunque en comparación con los sistemas flexivos de ambas lenguas), de un texto de tipo narrativo, entre lenguas sin tradición de traducción recíproca, y entre lenguas con sistemas gramaticales marcadamente diferentes (Cf. la noción de adecuación tipológica de Iturrioz y Ramírez 2012: 142). 


\section{Distinciones aspectuales en la morfología flexiva verbal en español}

Según García Fernández (1998), hay una diferencia entre modo de acción (también llamado aspecto léxico o aktionsart) (Vendler 1967) y aspecto gramatical (o simplemente aspecto). Comrie (1976) se refiere al aspecto como diferentes modos de contemplar la constitución temporal interna de una situación". Considerando este punto de vista, García Fernández (1998: 12) argumenta que:

Podríamos imaginar el aspecto como una lente o telescopio que nos permite contemplar de modo diferente una situación. El tipo de situación es determinado por el modo de acción [...] si la lente nos permite ver toda la situación, desde su principio hasta su fin hablamos de aspecto Perfectivo o Aoristo. Si la lente, en cambio, sólo nos permite ver una parte de la situación y no el principio o el fin, hablamos de aspecto Imperfecto. Si la lente lo que nos muestra son los resultados de un evento, entonces nos encontramos ante el aspecto Perfecto.

En español, García Fernández (1998: 13) reconoce cuatro variedades aspectuales:

\begin{tabular}{|l|l|l|}
\hline Aspecto & Forma verbal & Ejemplo \\
\hline IMPERFECTO & $\begin{array}{l}\text { presente } \\
\text { pretérito imperfecto }\end{array}$ & $\begin{array}{l}\text { Juan estudia biología } \\
\text { María estaba ayer en su } \\
\text { casa }\end{array}$ \\
\hline PERFECTIVO o AORISTO & $\begin{array}{l}\text { pretérito perfecto simple } \\
\text { todas las formas } \\
\text { compuestas con haber }\end{array}$ & $\begin{array}{l}\text { Mi perro se murió ayer } \\
\text { El rey había entrado a la } \\
\text { sala a las tres, como se tenía } \\
\text { previsto }\end{array}$ \\
\hline PERFECTO & $\begin{array}{l}\text { todas las formas } \\
\text { compuestas con haber }\end{array}$ & $\begin{array}{l}\text { A las tres los diputados ya } \\
\text { habían abandonado el } \\
\text { hemiciclo, que se } \\
\text { encontraba vacío }\end{array}$ \\
\hline NEUTRAL & $\begin{array}{l}\text { el futuro simple y el } \\
\text { condicional simple }\end{array}$ & $\begin{array}{l}\text { Juan estará mañana en } \\
\text { Madrid }\end{array}$ \\
\hline
\end{tabular}

Y, a su vez, reconoce tres variedades (a las que también llama formas) de aspecto imperfecto:

Progresivo, en el que se focaliza un único punto: A las cinco Juan escribía una carta, pero no sé si la terminó.

Imperfecto habitual, que aparece con predicados que expresan situaciones cuya repetición caracteriza a un sujeto: Siempre tomaba té para desayunar.

Continuo, es el tipo de aspecto que aparece con los predicados estativos: Era rubio o Tenía los ojos azules. 
García Fernández considera estas tres variedades instancias de una misma categoría aspectual y remarca que tanto el presente como el pretérito imperfecto son flexiones verbales inherentemente imperfectas, por lo que se espera que cada una de ellas tenga cualquiera de las lecturas anteriores.

\section{Categorías flexivas en el zapoteco de San Pablo Güilá}

Como se dijo antes, la flexión de las lenguas zapotecas es casi exclusivamente aspectual. Enseguida se muestra un esquema que representa la estructura morfológica de la palabra verbal en el zapoteco de San Pablo Güilá. Dicho esquema está basado en el análisis de López Cruz (1997: 83)

\begin{tabular}{|c|c|c|c|c|c|c|c|}
\hline \multirow{2}{*}{\multicolumn{2}{|c|}{ Prefijos de TAM }} & \multirow{2}{*}{$\begin{array}{c}\text { Prefijos } \\
\text { direccionales }\end{array}$} & \multirow{2}{*}{$\begin{array}{c}\text { Temas } \\
\text { verbales }\end{array}$} & \multirow{2}{*}{$\begin{array}{l}\text { Enclíticos } \\
\text { adverbiales }\end{array}$} & \multicolumn{3}{|c|}{ Enclíticos personales } \\
\hline & & & & & persona & sg. & pl. \\
\hline HABITUAL & $/ \mathrm{r}-/$ & ADLATIVO/ì-/ & & & 1 & $/=\hat{\sim} /$ & $/=n \breve{u} /$ \\
\hline PROGRESIVO & /ká-/,/z-/ & ABLATIVO/it-/ & & & 2 & $/=\underset{\sim}{\mathrm{u}} /$ & $/=\mathrm{du} /$ \\
\hline ESTATIVO & /nă-/ & & & & 3 RESPETO & $/=$ bă/ & /=răbă/ \\
\hline COMPLETIVO & $/ \mathrm{b}-/, / \mathrm{g}-/$ & & & & 3 FAMILIAR & $/=\mathrm{b} \breve{\mathbf{l}} /$ & /=răb̆// \\
\hline POTENCIAL & /gí -l & & & & 3 CONFIANZA & $1=3 \grave{a} /$ & /=rǎzà̀/ \\
\hline IRREAL & /nĭn-/ & & & & 3 ANIMAL & l=mă/ & l=rămă \\
\hline FUTURO & $/ \mathrm{z}-/, / \mathrm{r}-/$ & & & & 3 SUPRAHUMANO & $/=\mathrm{n} \breve{z} /$ & /=rănı̆?/ \\
\hline IMPERATIVO & $\begin{array}{l}\text { sg. /b-/ } \\
\text { pl. /gŭl-/ }\end{array}$ & & & & 3 INANIMADO & $/=n \breve{l} /$ & /=rănı̆/ \\
\hline
\end{tabular}

Como puede observarse, la lengua posee una posición prefijal inicial en la palabra, en la que se expresan los valores gramaticales correspondientes a las categorías de tiempo, aspecto y modo. Los valores de tipo aspectual son claramente predominantes ${ }^{2}$. Después de una posición para prefijos direccionales, viene la posición para las bases verbales -las cuales pueden ser raíces, formas derivadas o formas compuestas. Tradicionalmente se considera que las lenguas zapotecas no tienen sufijos. Así que los morfemas gramaticales que aparecen después de la base verbal no son sufijos sino enclíticos. Aparecen en primera instancia una serie de enclíticos facultativos que expresan valores aspectuales y modales, sobre los que no voy a ahondar. $\mathrm{Y}$ en una segunda posición enclítica, en el extremo final de la palabra, aparecen las marcas de persona que codifican al sujeto gramatical ${ }^{3}$. Enseguida se mues-

${ }^{2}$ De hecho, el único afijo que López Cruz considera dentro de la categoría Tiempo -el prefijo $/ \mathrm{z}-/ \sim / \mathrm{r}$ $/$ de futuro-, es un prefijo que se usa para codificar eventos poco probables. Aunque no es el tema esencial de este trabajo, una posibilidad analítica es considerar que el valor modo-aspectual de baja probabilidad sería el codificado flexivamente en este prefijo y que el valor temporal de futuro sería, en cambio, inferencial.

${ }^{3}$ Llama la atención la gran cantidad de enclíticos para tercera persona que usa la lengua. Estas distinciones de género tan abundantes -contrarias a lo que ocurre, por ejemplo, en las lenguas romances- son muy comunes en las lenguas del tronco otomangue al que pertenecen las lenguas zapotecas. 
tra un cuadro en el que se analizan los valores aspectuales, temporales y modales asociados con cada prefijo ( $c f$. López Cruz 1997: 85)

\begin{tabular}{|c|c|c|c|c|c|c|}
\hline \multirow{2}{*}{\multicolumn{2}{|c|}{ Prefijos de TAM }} & \multirow{2}{*}{$\begin{array}{l}\text { Contenido } \\
\text { aspectual }\end{array}$} & \multicolumn{3}{|c|}{ Lecturas temporales } & \multirow{2}{*}{ Modo } \\
\hline & & & PASADO & PRESENTE & FUTURO & \\
\hline HABITUAL & $/ \mathrm{r}-/$ & habitual & $\bar{l}$ & $\sqrt{1}$ & & \multirow{8}{*}{$\begin{array}{l}\text { realis/irrealis } \\
\text { realis/irrealis } \\
\text { realis } \\
\text { realis/irrealis } \\
\text { realis (probable) } \\
\text { irrealis } \\
\text { irrealis (dudoso) } \\
\text { imperativo }\end{array}$} \\
\hline PROGRESIVO & $/ \mathrm{kă}-/, / \mathbf{z}^{-} /$ & progresivo & $\sqrt{ }$ & $\sqrt{ }$ & $\sqrt{ }$ & \\
\hline ESTATIVO & /nă-/ & estativo & $\sqrt{ }$ & $\sqrt{ }$ & $\sqrt{ }$ & \\
\hline COMPLETIVO & $/ \mathrm{b}-/, / \mathrm{g}-/$ & completivo & $\sqrt{ }$ & & $\sqrt{ }$ & \\
\hline POTENCIAL & /gí-/ & prospectivo & & & $\sqrt{ }$ & \\
\hline IRREAL & /nĭn-/ & no realizado & $\sqrt{ }$ & & $\sqrt{ }$ & \\
\hline FUTURO & $/ \mathbf{z}-/, / \mathbf{r}-/$ & neutral & & & $\sqrt{ }$ & \\
\hline IMPERATIVO & $\begin{array}{l}\text { SG. /b-/ } \\
\text { PL. /gŭl-/ }\end{array}$ & ---- & & $\sqrt{ }$ & $\sqrt{ }$ & \\
\hline
\end{tabular}

De particular interés resulta el notar que los prefijos de aspecto progresivo y de aspecto estativo son compatibles con lecturas temporales de pasado, presente y futuro. El habitual, por su parte, es compatible con una lectura de pasado o de presente, pero no de futuro ${ }^{4}$. El aspecto completivo, en cambio, es compatible con las lecturas temporales de pasado y futuro, aunque no con la de presente, según López Cruz.

A continuación se muestran ejemplos de usos de los prefijos aspectuales: habitual, progresivo, estativo y completivo. Estos usos develan el conjunto de lecturas temporales con las que cada prefijo aspectual es compatible. Los ejemplos fueron tomados de López Cruz (1997: 86-106) y adaptados a las normas ortográficas empleadas en este trabajo:

Habitual /r-/: eventos rutinarios, habituales.
(1) a.
Rătè̀
txì
$\mathrm{r}$-àw=ră=bă
beěl
día $\quad \mathrm{H}$-comer $=\mathrm{PL}=3 \mathrm{R}$
carne

'Todos los días comen carne'
b. Nì>
pie
bûíny r-zà
gente $\mathrm{H}$-andar
tyěm=ğ
tiempo=DEM.DIST
'En aquellos tiempos la gente viajaba a pie'

4 Esto no es sorprendente dado que no se puede predicar sobre eventos recurrentes que no han ocurrido. Nótese, por ejemplo, que en español, de acuerdo con la propuesta de García Fernández, la categoría aspectual imperfecto - una de cuyas interpretaciones es, justamente, la habitual- se concretiza en las flexiones de presente y de pretérito imperfecto, pero nunca en una flexión de futuro. 
En el ejemplo (1a) la ausencia de un anclaje temporal dentro de la oración produce que el hábito designado por el predicado verbal se interprete temporalmente como vigente hasta el momento del habla (lectura de presente). En (1b) la construcción de carácter adverbial tyeemgi con valor de pasado ancla temporalmente el evento; como consecuencia, la interpretación es que el hábito designado por el predicado verbal ya no es vigente en el momento del habla (lectura de pasado). Nótese que aunque en ambas oraciones el verbo está flexionado con el prefijo habitual /r-/, las distintas lecturas temporales obligan a que en la traducción al español (1a) tenga una flexión de presente, y que (1b) tenga una flexión de pretérito imperfecto. Debe remarcarse que ambas flexiones del español son compatibles con el valor aspectual habitual que tiene el prefijo /r-/ en zapoteco.

Progresivo /Kă-/: eventos en desarrollo:
a. Gèt
kă $-\mathrm{kwâ}>=$ nŭ
tortilla
PROGR-echar $=1 \mathrm{P}$
'Estamos echando tortillas (al comal)'

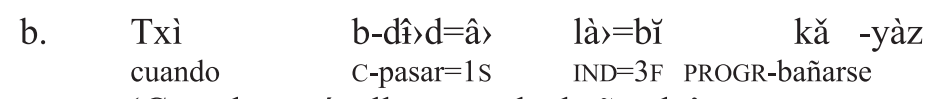

'Cuando pasé, ella se estaba bañando'

\begin{tabular}{|c|c|c|}
\hline $\begin{array}{l}\text { Kŭty } \\
\text { NEG }\end{array}$ & $\begin{array}{l}\mathrm{g}-\text { ŭnlà } \mathrm{z}=\mathrm{ù}\rangle \\
\text { POT-molestar }=2 \mathrm{~S}\end{array}$ & $\begin{array}{l}\text { là }\rangle=b \grave{~} \breve{t} \\
\mathrm{IND}=3 \mathrm{~F} \text { porque }\end{array}$ \\
\hline
\end{tabular}

'No lo molestes porque al rato va a estar chillando/se pone a chillar'

En (2a) la ausencia de un anclaje temporal hace que el evento en progreso se interprete como vigente en el momento del habla (lectura de presente). En (2b) el verbo de la oración subordinada adverbial está flexionado en completivo (con el prefijo /b-/) y ante la ausencia de un anclaje temporal dentro de la subordinada, el completivo se interpreta con una lectura temporal de pasado. En la medida en que la oración subordinada adverbial tiene interpretación de pasado se puede constituir en el anclaje temporal para el evento principal, el cual, por tanto, también tiene lectura de pasado. Finalmente, en (2c) es el adverbio de futuro gàstô 'al rato' el que se constituye en el anclaje temporal del evento en progreso, el cual, por lo tanto tiene lectura de futuro. Aunque los verbos principales de las tres oraciones tienen el mismo prefijo flexivo de aspecto progresivo /kă-/, la ausencia/presencia de elementos que funcionen como anclajes temporales hace que cada oración tenga una interpretación temporal distinta. En las traducciones al español, esto se refleja en el hecho de que aunque las tres oraciones comparten la construcción de progresivo de "estar + gerundio' difieren en la flexión temporal del verbo estar. 
Estativo/nă-/: eventos no dinámicos, ya se trate de estados físicos o mentales:
a. Nă-yàs
$\mathrm{ngul}=\mathrm{è \rangle}$
EST-dormir hombre=DIM
'El niño está durmiendo'

b. Txì

$\mathrm{b}-\mathrm{d} \hat{\mathrm{f} d}=\hat{\mathrm{a}}>$

nă-yàs=gă

ngul=èे

cuando

C-pasar $=1 \mathrm{~s}$

EST-dormir=todavía

hombre=DIM

'Cuando pasé, el niño todavía estaba durmiendo'

\begin{tabular}{|c|c|c|c|c|}
\hline Gŭl=sł̀̀dy & nà. & & bătì̀ & nă-yàs=dŭ \\
\hline
\end{tabular}

$\mathrm{Al}$ igual que con los dos prefijos aspectuales anteriores, la ausencia de un anclaje temporal en (3a) hace que la interpretación temporal sea la que se da por defecto, es decir la de presente. En (3b) el verbo de la oración subordinada está flexionado en completivo, cuya interpretación temporal por defecto es la de pasado en caso de que no haya un anclaje temporal. La lectura de pasado de la oración subordinada permite que ésta se constituya en el anclaje temporal en la cláusula principal por lo que ésta también tiene interpretación temporal de pasado. En (3c) es el adverbio $x \hat{\imath}$ 'mañana' el anclaje temporal que obliga a que la oración tenga una interpretación temporal de futuro.

Completivo /b-/: eventos concluidos (= con un límite final bien determinado) con relación a un punto de referencia temporal que puede situarse en el pasado o en el futuro.
a. $\quad$ B-yàb=â
C-caerse $=1 \mathrm{~s}$
'Me caí'
b. Nà̀y b-yŏ'=nŭ
ayer $\quad \mathrm{C}-\mathrm{ir}=1 \mathrm{P}$
'Ayer fuimos'
$\begin{array}{llll}\text { c. Xî̀ bă } \quad \text { b-ì̀̀ } & \text { lònì } \\ \text { mañana ya } & \text { C-terminar fiesta } \\ \text { 'Mañana ya habrá terminado la fiesta' }\end{array}$

La interpretación temporal por defecto para el completivo es la de pasado. Ésta ocurre cuando no hay anclaje temporal en la oración, como en (4a) y, por supuesto, también puede ocurrir cuando hay un anclaje temporal al pasado, como el que el 
adverbio temporal $n a \grave{\prime} y$ 'ayer' produce en (4b). Pero el completivo es compatible con una lectura de futuro cuando en la oración hay un anclaje temporal en ese tiempo, tal como el que produce el adverbio temporal $x \hat{\imath}$ 'mañana' en (4c). Este último caso es el que justifica la consideración de que /b-/ es un prefijo de aspecto completivo y no, por ejemplo, un prefijo de pasado perfectivo.

En resumen, hemos visto que los prefijos aspectuales del zapoteco de San Pablo Güilá son compatibles con distintas lecturas temporales. Estas lecturas temporales están motivadas por elementos de carácter adverbial que en el nivel oracional anclan al evento en un determinado tiempo. Así, por ejemplo, xî 'mañana' y gàstô 'al rato' producen anclajes temporales en el futuro, mientras que nà̀y 'ayer' y tye? mgi? 'en aquel tiempo' producen un anclaje temporal en el pasado. En ausencia de este tipo de constituyentes oracionales, la interpretación temporal se da por defecto. Los aspectos habitual, progresivo y estativo tienen por defecto una lectura de presente mientras que el completivo tiene por defecto una lectura de pasado. Queda claro que en el nivel flexivo, el zapoteco codifica exclusivamente valores aspectuales y que en el nivel oracional se pueden expresar valores temporales mediante el uso de recursos adverbiales. Si no se hace uso de estos recursos (i. e. si no hay anclaje temporal) entonces la interpretación temporal se asigna por defecto. Esta asignación por defecto es a lo que llamo inferencia. Uso ese término para distinguirla de aquel tipo de interpretación semántica que se sigue directamente de lo que está codificado formalmente en la expresión lingüística ${ }^{5}$.

\section{De vuelta a la flexión verbal en español}

Del mismo modo que en zapoteco los valores temporales pasado, presente y futuro no se codifican flexivamente, de modo que, o bien tienen que codificarse mediante recursos léxico-adverbiales en el plano oracional, o bien pueden no expresarse (lo que obliga al receptor a inferirlos), podemos asumir que en español los valores aspectuales habitual, progresivo y estativo no se codifican flexivamente de modo que el hablante de español tiene la opción de codificarlos mediante recursos léxicos adverbiales ( $p$. ej. siempre para el habitual), recursos perifrásticos ( $p . e j$. estar + gerundio para el progresivo), etc., o bien no expresarlos y obligar al receptor a que los infiera. No tendría mucho sentido en zapoteco proponer un valor temporal que incluyera, por ejemplo, al pasado y al futuro (al que se podría llamar 'tiempo no presente') para decir luego que el prefijo /b-/ marca tiempo no presente y aspecto completivo. Aún menos adecuado sería proponer un valor temporal que incluyera pasado, presente y futuro para decir que dicho valor es el expresado en los prefijos /r-/, /kă-/ y /nă-/. Siguiendo esta línea de razonamiento, habría que preguntarse el sentido que tiene hablar de un aspecto imperfecto en español si dicho

\footnotetext{
${ }^{5}$ Un caso de este tipo de inferencia en español sería el siguiente. En ausencia de un pronombre posesivo, los nombres inanimados se interpretan como posesiones de una primera persona: Tengo que mandar a revisar el automóvil. Es decir, en ausencia de una codificación expresa de poseedor, se interpreta que el auto es una pertenencia de quien habla.
} 
aspecto no se traduce a una sola lectura, sino a, al menos, tres lecturas distintas: progresivo, imperfecto habitual y continuo, siguiendo la terminología propuesta por García Fernández ${ }^{6}$. Más bien, habría que comenzar por reconocer que las flexiones de presente y pretérito imperfecto en español no tienen una sola interpretación aspectual sino tres. Y que el hecho de que una misma forma flexiva tenga tres lecturas posibles no significa que esas tres lecturas sean instancias de una misma entidad aspectual (pues, bajo ese razonamiento, el pasado, el presente y el futuro serían tres instancias de una misma entidad temporal en zapoteco). Más bien, habría que reconocer que el español es una lengua con una gran pobreza aspectual en el plano flexivo (de la misma manera que el zapoteco es una lengua con una enorme pobreza temporal en el plano flexivo). Y habría que reconocer, enseguida, que en una expresión como Siempre tomaba té para desayunar el elemento que determina la interpretación habitual inequívoca es el adverbio aspectual siempre y no la flexión de pretérito imperfecto. Debe notarse que la lectura habitual se conserva incluso si la flexión corresponde a un pretérito perfecto simple: Siempre tomó té para desayunar. Dicho de otra manera, la lectura habitual no es una instancia de un supuesto aspecto imperfecto, sino una entidad aspectual en sí misma, por derecho propio, que en algunas lenguas, como el zapoteco, se codifica flexivamente mientras que en otras lenguas, como el español, en las que no se codifica flexivamente, debe expresarse mediante recursos léxicos (como las expresiones adverbiales siempre, toda la vida, etc.).

De lo anterior, entonces, se puede concluir que no existe un aspecto imperfecto. La imperfectividad puede ser una característica (incluso podría ser un rasgo formal) de ciertas categorías aspectuales que en algunas lenguas constituyen una clase natural, pero que no necesariamente lo son en otras. Por lo tanto, PROGRESIVO, HABITUAL y CONTINUO no son variedades (ni formas) de una misma categoría aspectual sino que constituyen entidades aspectuales diferentes. Eso quiere decir que las formas de presente y de pretérito imperfecto en español no comparten una misma categoría aspectual sino que cada una de ellas carece del rasgo de perfectividad, lo que licita que puedan tener distintas interpretaciones contextuales, cada una de ellas correspondiente a una categoría aspectual distinta. Así entonces, el español es una lengua con una flexión aspectual casi nula, con lo que la expresión de las categorías aspectuales se delega a recursos léxicos adverbiales, tiempos verbales compuestos, etc. Por su parte, en zapoteco la flexión es predominantemente aspectual y es casi nula en la expresión de la temporalidad, la cual se delega a recursos léxicos y sintácticos.

\section{Dos estilos narrativos y dos usos del aspecto flexivo en español}

Centrémonos ahora en las flexiones de presente y pretérito imperfecto del español. Recordemos que según García Fernández, los verbos conjugados en dichas flexiones tienen como una de sus lecturas posibles la de eventos habituales. Desde el punto de

\footnotetext{
${ }^{6}$ Debe notarse que estas tres lecturas se corresponden de manera casi perfecta con los tres aspectos (codificados flexivamente) del zapoteco de San Pablo Güilá que he llamado, respectivamente, progresivo, habitual y estativo.
} 
vista narrativo, en español existen al menos dos estilos con relación al tipo de flexión usada. Por un lado, tenemos el estilo al que podemos llamar narración de cuentos de hadas (por ejemplo, los cuentos que las madres les cuentan a los hijos antes de que se duerman). En este estilo narrativo, los personajes se presentan y caracterizan mediante la enunciación de eventos que realizan habitualmente. Los verbos en este punto se flexionan típicamente en pretérito imperfecto. Posteriormente, se introducen situaciones específicas que constituyen el núcleo anecdótico de la narración. En este punto de la narración, los verbos se flexionan típicamente en pretérito perfecto simple. En español coloquial mexicano, como una transición entre ambas partes de la narración las primeras situaciones específicas se pueden codificar mediante verbos flexionados en presente simple. Desde el punto de vista aspectual tenemos una transición de lo habitual a lo perfectivo. Obsérvese el siguiente ejemplo, casi estereotípico?:

Fragmento de Cuento de hadas (Canción de Chava Flores)

[...] Como el rey era pobre ganaba

treinta míseros pesos al mes,

por supuesto que no le alcanzaba

para darse una vida de rey.

Y la reina lloraba y lloraba

con un perro pulguiento a sus pies.

$\mathrm{Y}$ de pronto se aparece un hada

que ha dejado a la reina de a seis.

Como el hada era un hada moderna

al perrito le echó DDT,

le prestó un paliacate a la reina

y le dijo: -¿Por qué llora usted? [...]

Los cuatro primeros verbos están flexionados en pretérito imperfecto y, claramente, no se refieren a eventos específicos ni centrales en la historia, sino a eventos rutinarios que sirven como telón de fondo para caracterizar a los personajes. La expresión adverbial $y$ de pronto anuncia el paso de los eventos habituales hacia los eventos específicos. Se esperaría en este punto un cambio de flexión hacia una forma perfectiva típica, como el pretérito perfecto simple. El uso de una forma de presente puede no ser la más adecuada para un español normativo, pero su uso en un español coloquial -al menos en la variante mexicana- está más que constatado ${ }^{8}$.

\footnotetext{
${ }^{7}$ Los verbos de las cláusulas principales están subrayados para su más fácil localización.

${ }^{8}$ Para algunos hablantes de español mexicano, para que el uso del presente en este contexto discursivo de introducción de eventos específicos suene natural es necesario que el verbo esté precedido por un que. Así, parece más aceptable decir Juan estaba leyendo tranquilamente y de pronto que llega María y lo asusta a decir Juan estaba leyendo tranquilamente y de pronto llega María y lo asusta. Por supuesto que, en general, el uso del pretérito perfecto simple es perfectamente posible en estos casos: Juan estaba leyendo tranquilamente. De pronto llegó María y lo asustó.
} 
Los verbos de cláusulas principales posteriores a la introducción del primer evento específico se flexionan en pretérito perfecto simple si se refieren a eventos específicos. Eso es lo que, de hecho, ocurre con los tres siguientes verbos en el ejemplo anterior. Todo lo anterior puede resumirse en el siguiente esquema:

Usos de las flexiones verbales en la narración de cuentos de hadas

\begin{tabular}{|l|l|c|c|}
\hline \multirow{2}{*}{} & Eventos genéricos (= habituales): & \multicolumn{2}{|c|}{ Eventos específicos: trama } \\
\cline { 3 - 4 } & presentación de los personajes & Iniciales & \multicolumn{2}{|c|}{ Posteriores } \\
\hline \hline Español estándar & pretérito imperfecto & \multicolumn{2}{|c|}{ pretérito perfecto simple } \\
\hline Español coloquial & pretérito imperfecto & presente & pretérito perfecto simple \\
\hline
\end{tabular}

En el primer caso, el paso de la descripción de los personajes mediante la enumeración de los actos que realizan cotidianamente a la trama se realiza abruptamente mediante un cambio de pretérito imperfecto a pretérito perfecto simple. En el segundo caso este cambio se da a través de un uso del presente.

Por otro lado, en las reseñas de películas y de libros los personajes también suelen introducirse mediante la enunciación de eventos que realizan habitualmente. Pero en este caso, los verbos se flexionan típicamente en presente simple. Posteriormente, se introducen situaciones específicas que constituyen el núcleo anecdótico de la narración. Los verbos típicamente se siguen flexionando en presente simple. La inclusión de formas verbales perfectivas se retrasa hasta la presentación de situaciones específicas que rompen la línea temporal, es decir que se refieren a un evento temporalmente anterior al que se describió con el verbo anterior del discurso. Obsérvese la siguiente reseña de la película Mulholland Drive (de David Lynch) $)^{9}$ :

Betty es una joven que vive en Canadá y trabaja haciendo papeles secundarios en películas baratas. Llega a Los Ángeles con la intención de convertirse en estrella de cine. Se aloja en el apartamento de su tía. Dentro de la casa se encuentra con Rita, una mujer amnésica que ha sufrido un accidente en Mulholland Drive. Juntas deciden investigar quién es Rita y cómo llegó hasta allí.

Los tres primeros verbos están flexionados en presente y tienen una interpretación genérica (estativa en los dos primeros casos, debido al aktionsart del propio lexema verbal y habitual en el tercer caso). El cuarto verbo, llegar, también está flexionado en presente pero en este caso ya no se refiere a un evento genérico sino a un evento específico, el primero de una serie que ya nos introduce en la historia: la protagonista llega, se aloja, se encuentra con Rita. Nótese que entre estos eventos no se rompe la linealidad temporal, es decir que el evento de llegar precede temporalmente al de alojarse y éste al de encontrarse con Rita. En el

\footnotetext{
9 Tomado de http://cinematicworld.wordpress.com/mulholland-drive-tan-confusa-como-fascinante/.
} 
resto del texto, las formas verbales continúan flexionándose en presente mientras la línea temporal se mantenga. Sólo los eventos que rompen la linealidad temporal son lo que no se flexionan en presente, sino que aparecen en formas perfectivas. Por ejemplo, el acto de sufrir un accidente Rita -que no está en presente, sino en antepresente- precede al acto de que se encuentren Rita y Betty. Obsérvese el siguiente esquema:

Usos de las reflexiones verbales en las reseñas de plículas y libros

\begin{tabular}{|c|c|c|c|}
\hline $\begin{array}{c}\text { Eventos genéricos (=habituales) } \\
\text { (presentación de los personajes) }\end{array}$ & Iniciales & $\begin{array}{c}\text { Posteriores que no rompen } \\
\text { la linealidad temporal }\end{array}$ & $\begin{array}{c}\text { Posteriores que rompen la } \\
\text { linealidad temporal }\end{array}$ \\
\cline { 2 - 4 } & presente & pretérito perfecto simple10 \\
\hline
\end{tabular}

Comparando los esquemas de ambos estilos narrativos se puede establecer la siguiente generalidad respecto del uso de las flexiones verbales en español en las narraciones:

$$
\text { pretérito imperfecto }>\text { presente }>\text { pretérito perfecto simple }
$$

Esto quiere decir que en una narración en español el uso del pretérito imperfecto antecede al uso del presente y que éste, a su vez, antecede al uso del pretérito perfecto simple (y otras flexiones de tipo perfectivo). Esta escala nos permitirá revalorar lo que ocurre en la traducción del cuento zapoteco Dăd gyà>l kùn büinynxăb (El señor del copal y el diablo) que el propio autor, Federico Luis Gómez, hace al español.

\section{Análisis de la flexión verbal en la traducción del cuento}

Por cuestión de espacio no se presenta el cuento en su totalidad, sino sólo la primera parte, en la que se introduce a los personajes y posteriormente, da comienzo la trama; ese el momento en que se presentan los primeros eventos específicos. Primero se presenta el cuento en zapoteco. Los verbos están señalados en negritas. La parte sombreada en gris byù 'tì gè $\underline{l}$, literalmente 'hubo una noche..." ${ }^{11}$ anuncia la aparición de los eventos específicos.

\footnotetext{
$10 \mathrm{Y}$ otras formas perfectivas similares como las formas compuestas con haber.

11 Una traducción más afortunada al español sería 'Pero una noche sucedió que...'.
} 
DǍD GYÀ̀L KÙN BÎI NYNXX̄̌B. Autor: Federico Luis Gómez.

Byù' tì †xì byù' tì đãdè> rùmbă zè>ny tì là'ny dăny dùxyà̀z. Là'ny dănygĭ rtè̀bă gyà̀lnàx. Kâd bè>w txŭ’ rdiè>bă rù' lìzbă, bă zêbă. Xpûrbă rù> xkètbă. Là̀gă xpûrbă rù> xàbìtxbă. Txŭ’ stìmă rzòpă. Txư’ gínà>zdì>bă nèz bă zêbă. Txŭ’ txì gízènybă là'ny dany rì̀ty rtyù'bă gyà̀ 1 rìsà'mbă răxpûrbă tì là'ny gúràlj rò'yà'z. Là'nygŭ rkàrămă mànì̀. Là>ìtxì xě, là ìtxì xě †xŭ' rièněbă làırămă rù' gì̀ù tí gyè'rămă nìs. Txì rìlò ryè'rămă nìs txŭ’ rìsà'nzàkbă là̀rămă

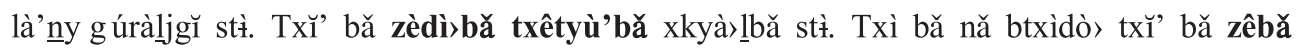
txìkà'bă là>rămă stì. Txŭ’ rkàdù> rămă gàxgà rù'blìè rì̀ty ràsybă. Txŭ’ txì sálòbă kwì̀kybă gì, rùntxè̀bă kàfề, rkì̀xbă gèt, ràwbă, rzŏpă rù' dè tì gítxá'bă. Txŭ’ txi gíkùdyàgbă nèz

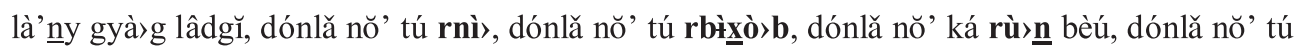

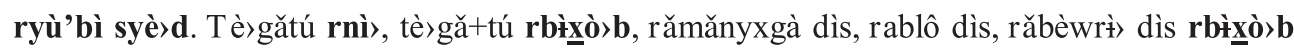

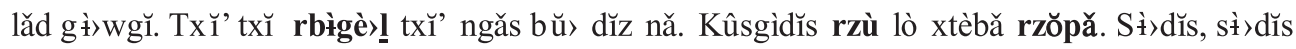
rzŏpă rù ' xtèbă rătè̀ gè)l. Txìgúldì>nĭ byù' tì gè̀l là̀răxpûrbă rxì̀rămă xì' rămă rzàlò rămă, rbìgyè rămă nì’rămă. Txŭ’ rnì>něbă là>rămă, gêbă: ¿tú rándù, bûrr? Txìgúldì̀nĭ kád mnădì̀ba kánèz bzà tì bnà> ntsà' yà'z, ntsà' lò tyèp, bzèny rù' xtèbă. Txŭ' rènǐ̀ lòbă tì nàırâ'

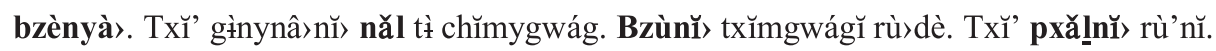

La narración comienza con un verbo existencial flexionado en completivo y duplicado para introducir un tiempo y al personaje principal Byù' tì txì byù 'tì dădadè $>$..., literalmente algo como 'Hubo una vez hubo un señor...'. Se trata de una construcción fosilizada muy usual al inicio de este tipo de narraciones ${ }^{12}$. Dejando de lado esta forma verbal, así como las ocurrencias de la cópula nǎ (dos) y del verbo existencial nŏ’ (cuatro) que no se flexionan, antes de que en la narración aparezcan eventos específicos tenemos cinco formas progresivas (irregulares por tratarse de verbos de movimiento 'ir' y 'venir'), ocho formas potenciales (algunas con /g-/ o /gí-/ y otras con mutación de la consonante inicial de la base verbal a favor de / $\mathbb{f} /$ ) $\mathrm{y}$ treinta formas flexionadas en habitual. Las formas progresivas se usan en construcciones coordinadas y de subordinación, lo mismo que las formas potenciale ${ }^{13}$. Obsérvese el siguiente ejemplo, correspondiente a la cláusula 8 del texto, en el se ilustra un tipo de coordinación ${ }^{14}$ :

12 Equivalente al Érase una vez... o Había una vez... de los cuentos de hadas en español. En español los verbos de estas construcciones fosilizadas están flexionados en pretérito imperfecto mientras que el verbo de la construcción fosilizada del zapoteco de San Pablo Güilá está flexionada en completivo.

${ }^{13}$ Las formas potenciales son obligatorias en oraciones subordinadas de finalidad

14 En la primera línea aparece la forma ortográfica, en la segunda la forma fonológica con cortes morfológicos, en la tercera las glosas y en las cuarta una traducción libre. Cabe aclarar que en los siguientes ejemplos la traducción libre es mía, no de Luis Gómez. 
Txŭ’ gínà>zdì̀bă nèz bàzêbă.

$\begin{array}{lllll}\text { t Jíi } & \text { gí-nàz }=\text { dì }=\text { bă } & \text { nèz } & \text { bă } & \text { zê=bă. } \\ \text { entonces } & \text { POT-tomar=entonces }=3 \mathrm{R} & \text { camino } & \text { ya } & \text { PROG.ir }=3 \mathrm{R}\end{array}$

Entonces agarraba camino y ya se iba.

Dicho de otro modo, algunas construcciones coordinadas y subordinadas obligan a que la flexión de uno de los verbos sea en potencial y la del otro en progresivo. Dejando de lado estos casos, lo que queda es treinta ocurrencias verbos flexionados en habitual, como se ilustra en el siguiente ejemplo, correspondiente a la segunda cláusula:

Là'nny dănygŭ rtè̀bă gyà lnàx.

\begin{tabular}{|c|c|c|c|}
\hline $\begin{array}{l}\text { là?ňj } \\
\text { panza }\end{array}$ & $\begin{array}{l}\text { dǎňj }=g \breve{1} \\
\text { cerro }=\text { DEM.N.V. }\end{array}$ & $\begin{array}{l}\text { r-tè }=\text { bă } \\
\text { H-recoger }=3 \mathrm{R}\end{array}$ & $\begin{array}{l}\text { gjă } \\
\text { copal }\end{array}$ \\
\hline
\end{tabular}

En esa montaña recogía copal dulce.

Todas las formas flexionadas en habitual y la mayoría de las formas en progresivo y en potencial que preceden a la aparición de los eventos específicos tienen una interpretación habitual y sirven para introducir el tipo de vida que lleva el protagonista del relato: cómo se va a trabajar al monte en compañía de sus burros y pasa varios días recolectando copal y durmiendo por la noche al lado de su fogata. La expresión byù' tì gè $\underline{l}$ al inicio de la cláusula 21 anuncia el inminente inicio de la trama principal, en la cual el primer evento importante es el encuentro del protagonista con un ser sobrenatural que adopta la forma de una mujer muy bella que llega caminando entre las sombras:

Txì gúldì>nŭ byù' tí gè>l là>răxpûrbă rxì̀ xì'nì̀ rzà lò rămă, rbígyè răma nì'rama

\begin{tabular}{|c|c|c|c|c|c|c|}
\hline $\begin{array}{l}\text { tigúldìnı̆ } \\
\text { entonces }\end{array}$ & $\begin{array}{l}\text { b-jù? tí } \\
\text { c-haber uno }\end{array}$ & $\begin{array}{l}\text { gè I } \\
\text { noche }\end{array}$ & $\begin{array}{l}\text { là }=\text { ră }= \\
\text { FOC-PL }=\end{array}$ & $\begin{array}{l}\int \text {-bûr }=\text { bă } \\
\text { POS-burro=3R }\end{array}$ & $\begin{array}{l}\mathrm{r}-\int_{\sim}^{\mathrm{i}}=\mathrm{ră}=\mathrm{mă} \\
\mathrm{H}-\mathrm{sonar}=\mathrm{PL}=3 \mathrm{AN}\end{array}$ & $\begin{array}{l}3 \grave{i}=\mathrm{ră}=\mathrm{mă} \\
\text { naríz }=\mathrm{PL}=3 \mathrm{AN}\end{array}$ \\
\hline & ră $=$ mă & r-bát + & & ră=mă & nì $=$ ră $=$ mă & \\
\hline $\operatorname{ar}$ & $\mathrm{PL}=3 \mathrm{ANIM}$ & H-pon & $\mathrm{r}+$ piedra & $\mathrm{PL}=3 \mathrm{ANIM}$ & $\mathrm{pie}=\mathrm{PL}=3 \mathrm{ANIM}$ & \\
\hline
\end{tabular}

Entonces hubo una noche en que sus burros empezaron a rebuznar y a azotar sus pies.

Todavía en esta cláusula los verbos aparecen flexionados en habitual, pero ya no se refieren a eventos habituales, sino a eventos iterativos: rebuznar y azotar los pies. En la siguiente cláusula el protagonista les pregunta a sus burros por qué están nerviosos. Y en la cláusula 23 aparece la primera forma verbal auténticamente flexionada en completivo: el verbo $n a ̆$ 'ver, percatarse':

Txì gúldìnň kád mnădì bǎ kánèz bzà tí bnà ntsà'yà'z, ntsà' lò tyèp, bzèny rù' xtèbǎ.

tigúldìnı̆ kád b-nă=dì=bă ká+nèz b-zà tí bnà ntsà?=jà?z

entonces NEG C-ver $=$ entonces $=3 \mathrm{R} \quad$ dónde + camino $\mathrm{c}$-andar uno mujer hermoso $=$ INTS

No se percató ni por donde llegó caminando una hermosa mujer-ciegamente bella-, hasta el lado de su fogata. 
A partir de allí, la ocurrencia de verbos flexionados en completivo se vuelve la norma. En el resto del fragmento citado, hay ocho verbos: seis de ellos están flexionados en completivo, uno en habitual (se trata de un verbo de comunicación, los cuales normalmente se flexionan en habitual en zapoteco) y un verbo posicional năl que significa algo como 'traer colgado del brazo' el cual está flexionado en estativo.

En términos generales, dejando de lado los casos de verbos en cláusulas coordinadas y subordinadas, puede decirse que en zapoteco de San Pablo Güilá en una narración los eventos genéricos se codifican mediante una flexión habitual y los eventos específicos lo hacen mediante una flexión de completivo:

Usos de las flexiones verbales en narraciones en zapoteco de San Pablo Güilá

\begin{tabular}{|c|c|}
\hline $\begin{array}{c}\text { Eventos genéricos (= habituales): presentación } \\
\text { de los personajes }\end{array}$ & Eventos específicos: trama \\
\hline \hline habitual & completivo \\
\hline
\end{tabular}

Veamos, finalmente, la traducción del texto que hizo al español Luis Gómez: Gómez.

EL SEÑOR Y EL DIABLO (fragmento). Traducción al español de Federico Luis

Hubo un día un señor que trabajaba en una montaña muy grande. En esa montaña recogía copal dulce. Cada mes salía de su casa y se iba. Su burro cargaba sus tortillas. El mismo burro cargaba su cobija. Él montaba otro burro. Entonces tomaba camino y ya se iba. Entonces cuando llegaba a la montaña en la que recolectaba el copal iba a dejar a sus burros a un potrero grande. Allí amarraba las patas de sus burros. A las doce en punto, los llevaba al río para que bebieran agua. Cuando terminan de beber agua entonces los va a dejar de nuevo al potrero (otra vez). Entonces ya se va a recolectar su copal de nuevo. Cuando ya es muy tarde, entonces ya los va a traer otra vez. Entonces los amarra cerca de la cueva donde duerme. Entonces es cuando empieza a poner la lumbre, prepara su café, tuesta la tortilla para comer, se sienta al lado de la fogata para calentarse. Entonces, calladito va a escuchar del otro lado del cerro, para saber si alguien habla, a ver si alguien grita, para saber si en alguna parte aúllan los coyotes, para saber si alguien viene haciendo ruido. Nadie habla, nadie grita, solamente los pájaros, los zanates, las cigarras gritan entre esos cerros. Entonces cuando la noche cae se pone muy obscuro. Sólo las chispas salen de su fogata cuando se encuentra sentado. Siempre, siempre, todas las noches se sienta alrededor de su fogata. Entonces hubo una noche que sus burros empezaron a sonar sus narices, empezaron a azotar sus pies. Cuando él les habla, les dice: ¿Qué ven, burros? No se percató ni por donde llegó caminando una hermosa mujer, ciegamente bella, cerca de su fogata. Entonces ella le dijo: ya llegué. De su brazo traía colgado un chiquihuite. Ella puso el chiquihuite cerca de la fogata. Entonces lo abrió.

Lo primero que llama la atención es que el primer verbo, el que corresponde a la frase fosilizada con el verbo byù' ('haber' en completivo), lo traduce como un pretérito perfecto simple y no con el pretérito imperfecto de la frase había una vez.... Pero a partir de allí, hay una enorme cantidad de formas de pretérito imperfecto 
entre las cuales sólo aparece la forma en subjuntivo bebieran en la oración subordinada de finalidad para que bebieran agua. Esas formas en pretérito imperfecto son traducciones, casi todas, de formas en habitual. Esto no resulta sorprendente pues una de las lecturas posibles en las formas de pretérito imperfecto en español es justamente la habitual. Pero de modo inexplicable desde la perspectiva del español, hay un cambio abrupto: los verbos dejan de flexionarse en pretérito imperfecto y comienzan a flexionarse en presente (esto se señala en la traducción con un sombreado en gris). Reproduzco aquí ese pequeño fragmento que ilustra el cambio de pretérito imperfecto a presente:

Allí amarraba las patas de sus burros. A las doce en punto, los llevaba al río para que bebieran agua. Cuando terminan de beber agua entonces los va a dejar de nuevo al potrero.

Si se revisa el cuento en zapoteco -en las cláusulas 9 a 11- se puede ver que la motivación de este cambio tampoco está en la flexión del zapoteco, pues en todas estas cláusulas los verbos se flexionan en habitual. Es decir, la flexión en zapoteco no cambia pero la del español sí:

$\begin{array}{llll}\text { Texto en zapoteco: } & \text { habitual } & \text { continúa } & \text { en habitual } \\ \text { Traducción al español: } & \text { pretérito imperfecto } & \text { cambia a } & \text { presente }\end{array}$

La motivación de este cambio abrupto no está en la gramática de ninguna de las dos lenguas, sino en el conflicto de lo que está codificado y lo que está inferido en cada una de ellas. La mejor explicación consiste en que, en realidad, no hay ningún cambio abrupto porque lo que Luis Gómez hace en su cuento no es describir los eventos que caracterizan al personaje principal en tiempo pasado o en tiempo presente, sino en aspecto habitual. Lo importante en su narración no es el tiempo en que el lector lo pueda ubicar, sino el que se trata de eventos que el personaje principal realiza cotidianamen$t^{15}$. Con esa preocupación en mente, su traducción al español intenta conservar ese sentido habitual y, dado que en español tanto el pretérito imperfecto como el presente son compatibles con la lectura habitual, la sustitución de una flexión por la otra no cambia en lo esencial el sentido de lo que quiere expresar. Desde esta perspectiva y sólo desde esta perspectiva, se trata de formas equivalentes y completamente intercambiables. Esta sustitución podría haber ocurrido en cualquier punto de la narración en que en el texto original las formas están flexionadas en habitual. Ayuda también el hecho de que en español tanto las formas de pretérito imperfecto (en los cuentos de hadas) como las de presente (en las reseñas de películas y libros) se pueden usar en textos narrativos. Lo único que se podría especular es que este cambio abrupto de flexión irá normalmente del pretérito imperfecto al presente, pero no al revés, siguiendo la tendencia general en las narraciones del español mencionada antes:

15 A la pregunta expresa que le hice de si la parte inicial de su narración estaba en presente o en pasado su respuesta, después de pensarlo bastante, fue un contundente: "No lo sé". 


$$
\text { pretérito imperfecto }>\text { presente }>\text { pretérito perfecto simple }
$$

Para corroborar esta hipótesis será necesario analizar una mayor cantidad de traducciones.

\section{Referencias bibliográficas}

Arellanes Arellanes, F., «Criterios en la elaboración de un sistema de escritura para el zapoteco de San Pablo Güilá», en: Sotelo Santos, L. E. (coord.), Jornadas Filológicas 2007. México: IIFL-Universidad Nacional Autónoma de México 2007.

Arellanes Arellanes, F., El sistema fonológico y las propiedades fonéticas del zapoteco de San Pablo Güilá. Descripción y análisis formal. Tesis doctoral: Colegio de México 2009.

BLACK, C. A., Quiegolani Zapotec Sintax: A Principles and Parameters Account. Dallas: SIL International and University of Texas (Arlington Publications in Linguistics 136) 2000.

Comrie, B., «Aspect». An Introduction to the Study of Verbal Aspect and Related Problems. Cambridge: Cambridge University Press 1976.

Garcia Fernandez, L., El aspecto gramatical en la conjugación. Cuadernos de Lengua Española. Madrid: Arco Libros 1998.

ItURRIOZ LeZA, J. L. / Ramírez de la Cruz, J., «El proceso de traducción entre español y huichol», Estudios de traducción 2 (2012), 133-145.

López Cruz, A., Morfología verbal del zapoteco de San Pablo Güilá. Tesis de licenciatura. Escuela Nacional de Antropología e Historia: México 1997.

Marlett, S. A. / PicketT, V. B., «The syllable structure and aspect morphology of Isthmus Zapotec», International Journal of American Linguistics 53 (1987), 398-422.

MeL'CuK, I., «Modelo formal de la conjugación española», Voz y Letra 4. Madrid: Arco Libro (1993), 9-85.

SмIтH, C. S., The Parameter of Aspect. Texas: Kluwer Academic Press 1997.

SuÁREZ, J. A., The Mesoamerican Indian languages. Cambridge: Cambridge University Press 1983.

VendLer, Z., Linguistics in Philosophy. Ithaca, N.Y.: Cornell Univ. Press 1967. 